\title{
PRENATAL AND POSTNATAL EFFECT OF LEAD ACETATE ON THE HISTOLOGY OF FRONTAL CORTEX AND MOTOR ACTIVITY IN WISTAR RATS
}

\author{
SALEH NUHU*, HAUWA IDRIS AHMAD, AISHA MUHAMMAD GARBA, TASIU ABDULLAHI SULAIMAN \\ Department of Human Anatomy, Faculty of Basic Medical Sciences, Yusuf Maitama Sule University, Kano, Nigeria. \\ Email: nuhusaleh88@gmail.com
}

Received: 09 September 2021, Revised and Accepted: 19 October 2021

\section{ABSTRACT}

Objectives: The objective of this study was to find the histologic and motor activity effect of lead on prenatally and postnatally exposed Wistar rats.

Methods: In this study, twelve Wistar Rats were used and grouped into four groups of two females and one male. Group I rats served as the control and allowed feed and water freely. The rats in Group II were administered 500 ppm of Pb through drinking water from gestation day 8 (GD8) to parturition (GD21). While Group III rats were given 500ppm of Pb in drinking water from postnatal day 1 (PND1) to PND21. The rats in the fourth group (Group IV) were given 500ppm of Pb from GD8 to PND21. Palmer grasp reflex was conducted to assess the motor activity of the rat pups. The animals were then humanely sacrificed and the frontal cortices were isolated for routine histological processing.

Results: The histological study has shown normal neurons in the control group while degenerating cells exhibiting karyolysis, pyknosis, karyorrhexis, vacuolation were seen in the lead-treated groups. Group II and Group IV showed considerate deficit in their motor activity while Group III showed mild effect.

Conclusion: From this study, lead exposure of Wistar rats at both prenatal and postnatal period of development has effect on the histology of the frontal cortex as well as on their motor activity.

Keywords: Lead, Frontal cortex, Prenatal, Postnatal, Motor activity, Palmer grasp reflex.

(C) 2021 The Authors. Published by Innovare Academic Sciences Pvt Ltd. This is an open access article under the CC BY license (http://creativecommons. org/licenses/by/4.0/) DOI: http://dx.doi.org/10.22159/ijms.2021v9i6.43098. Journal homepage: https://innovareacademics.in/journals/index.php/ijms

\section{INTRODUCTION}

Lead $(\mathrm{Pb})$ is a heavy metal well known from the history of mankind to the present day for its diverse uses, misuses, and toxicity. Even after the enactment of laws and regulations against the damaging use, still there are sporadic cases where the excess amount of $\mathrm{Pb}$ is being used. Once ingested orally in the food, from the environment, in mother's milk to infants, or through placenta in fetus, the $\mathrm{Pb}$ is slowly absorbed into the gastrointestinal tract [1].

According to Aprioku and Siminialayi (2013) [2], Pb is a heavy metal and environmental pollutant which occurs naturally as $\mathrm{Pb}$ oxide or $\mathrm{Pb}$ salts [3]. With its characteristic (dense, ductile, malleable, and corrosionresistant) properties, the metal has wide industrial applications in modern society. $\mathrm{Pb}$ is being used in production of paints, batteries, water pipes, gun bullets, $\mathrm{x}$-ray, and atomic radiation protection, eye cosmetics, base metal utensils, and also as additive in gasoline [4].

The frontal cortex of the brain (cerebrum) plays a vital role in speech and language production, some motor skills, comparing objects, forming memories, forming personality, and managing attention [5].

$\mathrm{Pb}$ is a highly neurotoxic agent affecting the developing central nervous system [6,7] through its interference of the cholinergic system and regulatory action of calcium on cell functions thereby disrupting many intracellular biological activities [8]. The alteration in this biochemical intercellular communication may precede neurobehavioral and neurological end points, usually observed in lead neurotoxicity [7].

Therefore, this study was conducted to find the effect of lead on the frontal cortex and motor activity of prenatally and postnatally exposed Wistar rats.

\section{METHODS}

Experimental animals

After obtaining ethical approval from the Ethics Committee on Animal Use and Care, Yusuf Maitama Sule University, Kano, a total of 24 (8 males and 16 females) adult Wistar rats from the animal house of the Department of Pharmacology, Bayero University, Kano, were used for the study. The animals were kept to acclimatize for 14 days in an animal house in the department of Human Anatomy, Yusuf Maitama Sule University, Kano. They were fed on a commercial pellet diet and allowed access to food and distilled water ad libitum.

\section{Animal grouping}

Two females with regular oestrus cycle were selected in the pro-oestrus stage and caged together with one male overnight. The $1^{\text {st }}$ day of gestation was determined by the presence of sperms in the vaginal smear $[9,10]$. Pregnant female rats were then placed in different cages at $1^{\text {st }}$ day of pregnancy. The animals were grouped as follows:

Group I (Control): This group consists of six rats, two males and four females. The normal control group will be fed food and distilled water ad libitum.

Group II (Prenatal exposure): This group is made up of six rats, two males, and four females. The female rats in this group were exposed to $500 \mathrm{ppm}$ of $\mathrm{Pb}$ acetate (BDH Chemicals Ltd, Product No.: 29021, Poole England) in distilled drinking water of the mother from the $6^{\text {th }}$ gestation day (GD) to GD21 [11,12].

Group III (postnatal exposure): Six rats, two males, and four females were used in this group. The female rats were exposed to $500 \mathrm{ppm} \mathrm{Pb}$ acetate in their distilled drinking water from postnatal day 1 (PND) to PND21. 
Group IV (gestation through lactation exposure): Six albino Wistar rats, four females and two males were used in this category. The rats were exposed to $500 \mathrm{ppm}$ lead acetate in distilled water of the mother from the $6^{\text {th }}$ day of gestation (GD6) to parturition and continued up to PND 21 and stopped at weaning [13]. The time span of GD6 to PND 21 was chosen to allow for embryo implantation in utero, and to maximize the effect of developmental $\mathrm{Pb}$ exposure, given that [14] found higher blood $\mathrm{Pb}$ levels at the later stages of gestational exposure.

\section{Route of administration}

The different concentration of lead acetate was administered through drinking water. This is based on the method used by [15], which resulted in causing lead poisoning in the rat pups.

\section{Duration of lead exposure}

The duration of the experiment was different from the groups. Group I animals serves as control where the group II animals will be exposed to lead acetate from the GD 6 to parturition while group III animals were exposed from parturition up to the $21^{\text {st }}$ day postnatally. The fourth group animals were exposed from GD6 to parturition and continued to PND 21. The fetuses in each group at the end of their period of $\mathrm{Pb}$ exposure were anaesthetized with ether (Trust Chemical Laboratories, Cat No. 67663, Hangzhou, China) and their whole brain was removed by opening the calvarium through the sagittal sutures.

\section{Histological tissue processing}

The harvested tissues were immediately fixed in Bouin's solution (319.18M, pH 2) for $24 \mathrm{~h}$ before the frontal cortices were isolated and subjected to routine histological processing based on the method of [16]. This was conducted in the Department of Human Anatomy, Yusuf Maitama Sule University, Kano.

\section{Motor activity}

Palmer grasp test; an object was placed in the hand of the pups with the fingers close and tightly grasping the object [17]. A stopwatch was used to record the time taken for the pups to hold on to the object.

\section{Statistical analysis}

Data obtained from the motor activity was expressed as mean \pm SEM using statistical package for service solution ([SPSS] IBM Corp, Version 21). Values of $\mathrm{p}<0.05$ were considered statisticslly significant.

\section{RESULTS}

\section{Histological evaluation of the frontal cortex}

The H\&E micrographs of Plate Ia and Plate Ib are representative section of Group I, at lower and higher magnifications, showing the normal cytoarchitecture of the frontal cortex of Wistar Rats with distinct pyramidal cell at both euchromatic and heterochromatic states.

Photomicrographs of Plates 2a and b are sections of frontal sections of rats administered $500 \mathrm{ppm}$ of lead acetate from GD6 to parturition (Group II). The sections demonstrate showing areas of mild fibrosis and degenerating neurons (DN) at various stages; karyolysis (KL) and karyorrhesis $(\mathrm{KH})$.

Plate $3 \mathrm{a}$ and $\mathrm{b}$ are photomicrograph of a section of Wistar rat's frontal cortex administered 500ppm of lead acetate from PND1 to PND21. They are characterised by neuropil vacuolation, perivascular vacuolation and $\mathrm{DN}$; KL, pyknosis and KH.

The H\&E micrographs of Plate $4 \mathrm{a}$ and $\mathrm{b}$ administered $500 \mathrm{ppm}$ of lead acetate from GD6 to PND21. It featured swollen astrocyte (AST) or Alzheimer type II cells, discontinuous blood capillaries (DC), karyolytic (KL) and karyorrhexic neurons, and vascuolarized pyramidal neurons.

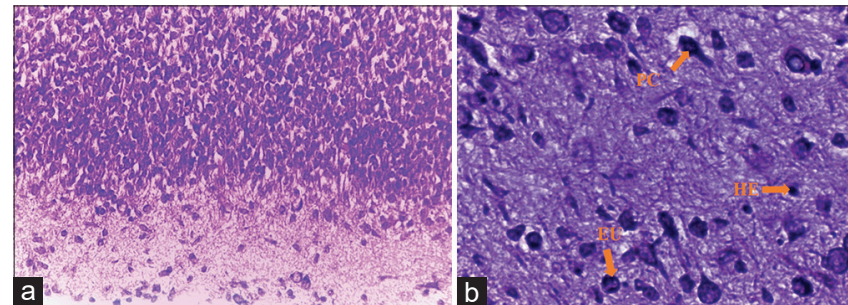

Plate 1: (a) Photomicrograph of a section of the frontal cortex of Wistar rat group I (control) showing normal architecture of the frontal cortex $(\mathrm{H} \& \mathrm{E} \times 400)$. (b) Photomicrograph of a section of the frontal cortex of Wistar rat in Group I showing cortical pyramidal cells with their nuclei at both euchromatic and heterochromatic state $(\mathrm{H} \& \mathrm{E} \times \mathbf{1 0 0 0})$

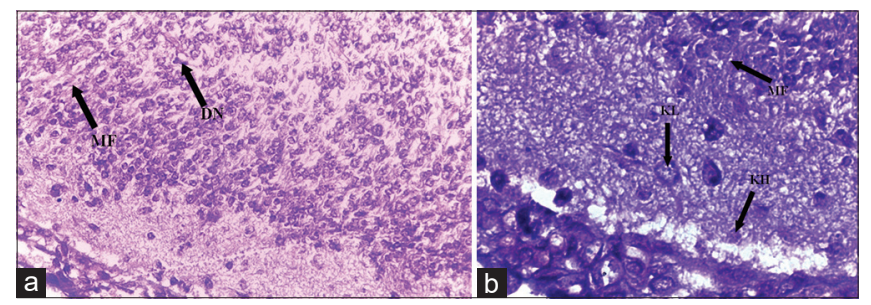

Plate 2: (a) Photomicrograph of a section of frontal cortex of Wistar rat exposed to 500ppm of lead acetate from GD6 to parturition showing areas of mild fibrosis, degenerating neurons (H\&E ×400). (b) Photomicrograph of a section of the frontal cortex of Wistar rat administered 500ppm from GD6 to parturition (prenatal group) showing a Karyolitic neuron, karyorrhexic as well as areas of mild fibrosis $(\mathrm{H} \& \mathrm{E} \times 1000)$
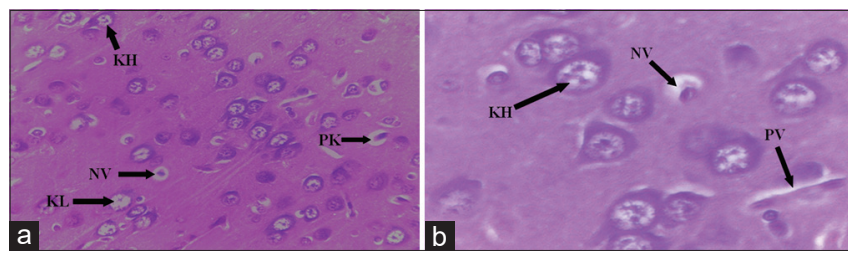

Plate 3: (a) Photomicrograph of a section of Wistar rat's frontal cortex administered $500 \mathrm{ppm}$ of lead acetate from PND1 to PND21. It is characterized by neuropil vacuolation and degenerating neurons; karyolysis, pyknosis, and karyorrhesis (H\&E ×600). (b) Photomicrograph of a section of the frontal cortex of Wistar rat administered 500 ppm of lead acetate from PND1 to PND21 showing Karyorrhexic neuron, neuropil vacuolation $(\mathrm{KH})$ as well as Perivascular Vacuolation (H\&E × 1000)

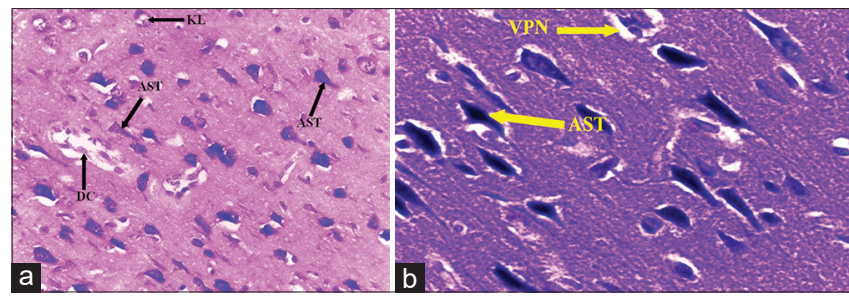

Plate 4: (a) Photomicrograph of a section of the frontal cortex of Wistar rat administered 500ppm from GD6 to weaning, showing numerous astrocytes (AST), discontinued capillaries and karyolitic neurons (H\&E $\times 400)$. (b) Photomicrograph of a section of the frontal cortex of Wistar rat administered $500 \mathrm{ppm}$ from GD6 to weaning, showing numerous swollen astrocytes or Alzheimer type II cells and vacuolarized pyramidal neurons. $(\mathrm{H} \& \mathrm{E} \times 1000)$ 
Table 1: One-way analysis of variance of the time taken for the rats to hold on to the hanger

\begin{tabular}{lllll}
\hline Time (s) & \multicolumn{2}{c}{} & \multirow{2}{*}{ P value } \\
\cline { 1 - 4 } Group I & Group II & Group III & Group IV & \\
\hline $18.5 \pm 1.291^{\mathrm{a}}$ & $12 \pm 2.160^{\mathrm{a}}$ & $13.75 \pm 2.06^{\mathrm{a}}$ & $12.5 \pm 1.291^{\mathrm{a}}$ & 11.503 \\
\hline Values are mean+SD. Similar superscripts indicate significant differences across the rows at P<0.05 & $0.0008^{* * *}$ \\
\hline
\end{tabular}

\section{DISCUSSION}

The frontal cortex is responsible for problem solving, judgement, and motor function [18]. The cerebral cortex of lead-induced Wistar rats shows few degenerating cortical and pyramidal neurons as shown in this study. This is in agreement with the findings of [18].

The observation of Alzheimer type II AST has been previously reported by Hazell et al. (2006) and Nuhu, (2017) [19,20] which explained that increased activity of reactive oxygen species is the cause of Alzheimer type II AST.

Clear cytoplasm, swelling of the axon, degeneration of the nerve cells, vacuolization and necrosis of the brain cells, and glial cell reaction were also reported from other heavy metal studies [21,22].

The degenerative changes seen occur because neuronal mitochondrial activity is affected by lead, with disruptive effects on synaptic transmission in the brain. Lead picked up by mitochondria produced swelling and distortion of mitochondrial cristae, uncoupled energy metabolism, inhibit cellular respiration, and altered calcium kinetics flow [19,23].

Lead intoxication in rats during the early postnatal period, with doses that approximate those in children, induced transient as well as persistent dysfunctions in exploratory behavior and motor skills [23]. These observed actions of lead may be related to impaired maturation of sensitive brain regions which develop postnatally. The present study has indicated a significant difference in the hand grasping ability among the lead treated groups at different stages of development and the control, with the highest time $(18.5 \pm 1.291)$ observed in the control and the least $(12 \pm 2.160)$ in the group exposed during gestation only (Table 1).

In a related study conducted by Grant et al. (1980) [24], motor activity was not affected except pivoting activity at day 14 of age in the group administered $250 \mathrm{ppm}$ of lead acetate only. This may be due to the dosage of the administered lead acetate.

It was also found in the Cincinnati lead study that prenatal and postnatal blood $\mathrm{Pb}$ levels were associated with poorer scores on assessments of bilateral coordination, upper-limb speed, and dexterity, and a composite index of fine-motor coordination [25].

\section{CONCLUSION}

In this study, lead toxicity has shown histological effects and motor impairment. Histopathological observations in lead-induced Wistar rat frontal cortex showed degeneration of cortical and pyramidal neurons causing scattered and shrunken neuronal cells with deeply stained cytoplasm, pyknotic nuclei and karyolitic nuclei. There was massive increase in vacuoles of affected neurons. The motor activity as demonstrated by the palmer grasp test has been impaired.

\section{REFERENCES}

1. Naqi SZ. A Comparative study of the histological changes in cerebral cortex, hippocampus, cerebellum, pons and medulla of the albino rat due to lead toxicity. Int J Anat Res 2015;3:1173-8.

2. Aprioku JS, Siminialayi IM. Maternal lead exposure and pregnancy outcome in Wistar albino rats. J Toxicol Environ Health Sci 2013;5:185-93.

3. Adikwu E, Deo O, Geoffrey OP, Enimeya DA. Lead organ and tissue toxicity: Roles of mitigating agents (Part 1). Br J Toxicol Pharm 2013;4:232-40

4. Thurtle N, Greig J, Cooney L, Amitai Y, Ariti C, Brown MJ, et al.
Description of 3, 180 courses of chelation with dimercaptosuccinic acid in children $\leq 5 \mathrm{y}$ with severe lead poisoning in Zamfara, Northern Nigeria: A retrospective analysis of programme data. PLoS Med 2014;11:e1001739.

5. Iliyasu MO, Ibegbu AO, Sambo JS, Musa SA, Akpulu PS. Histopathological changes on the hippocampus of adult wistar rats exposed to lead acetate and aqueous extract of psidium guajava leaves. Afr J Cell Path 2015;31:26-31.

6. Bazrgar M, Goudarzi I, Abrari K, Salmani ME, Lashkarbolouki T. Effect of postnatal chronic lead exposure on spatial learning and memory in male rat. Zahedan J Res Med Sci 2015;17:e1050.

7. Ghareeb DA, Hussien HM, Khalil AA. Toxicological and Environmental chemistry toxic effects of lead exposure on the brain of rats: Involvement of oxidative stress, inflammation, acetylcholinesterase, and the beneficial role of flaxseed extract. Toxicol Environ Chem 2010;92:37-41.

8. Ahmed MB, Ahmed MI, Meki AR, Abdraboh N. Neurotoxic effect of lead on rats: Relationship to apoptosis. Int J Health Sci (Qassim) 2013;7:192-9.

9. McClain RM, Becker BA. Teratogenicity, fetal toxicity, and placental transfer of lead nitrate in rats. Toxicol Appl Pharmacol 1975;31:72-82.

10. Azza AA, Hebatalla IA, Asmaa IA. Protective effect of zinc against postnatal lead-induced alterations in the neurobehavioural development of normally-fed and protein malnourished rats. J Neurol Neurosci 2016;7:117.

11. Goma UE, Mahrous AA. Changes in behavior and learning ability of rats intoxicated with lead. Int Sch Sci Res Innov 7 2013;7:1096-102.

12. Basha MR, Murali M, Siddiqi HK, Ghosal K, Siddiqi OK, Lashuel HA, et al. Lead $(\mathrm{Pb})$ exposure and its effect on APP proteolysis and Abeta aggregation. FASEB J 2005;19:2083-4.

13. Reddy GR, Devi BC, Chetty CS. Developmental lead neurotoxicity: Alterations in brain cholinergic system. Neurotoxicology 2007;28:402-7.

14. Bunn TL, Parsons PJ, Kao E, Dietert RR. Exposure to lead during critical windows of embryonic development: Differential immunotoxic outcome based on stage of exposure and gender. Toxicol Sci 2001; 64:57-66.

15. Rao Barkur R, Bairy LK. Evaluation of passive avoidance learning and spatial memory in rats exposed to low levels of lead during specific periods of early brain development. Int J Occup Med Environ Health 2015;28:533-44.

16. Bancroft JD, Gamble M. Theory and Practice of Histological Techniques. $6^{\text {th }}$ ed. London: Churchill Livingstone, Elsevier; 2008.

17. Lockman J. Advances in Child Development and Behavior. $1^{\text {st }}$ ed., Vol. 61. United States: Academic Press; 2021.

18. Highab SM, Magaji RA, Muhammad BY. Effect of lead poisoning and antidepressant drug on the cerebral cortex of the Wistar rats. Acta Sci Pharm Sci 2018;2:16-21.

19. Hazell AS, Normandin L, Norenberg MD, Kennedy G, Yi JH. Alzheimer type II astrocytic changes following sub-acute exposure to manganese and its prevention by antioxidant treatment. Neurosci Lett. $2006 \mathrm{Apr}$ 3;396(3):167-71.

20. Nuhu S. Effect of Lead on the Histology of Medulla Oblongata, Body Weight and Haematological Profile in Albino Wistar Rats, M.Sc, Bayero University, Kano, Nigeria; 2017.

21. Anitha KS. Effect of Water Pollution on LDH Isoenzymes in Fish from Hussain Sagar Lake, Ph.D, Osmania University, Hyderabad, India; 1998.

22. Jagannath BM. Effect of heavy metals on the histopathology of gills and brain of fresh water fish Catla catla. Biomed Pharm J 2013;6:99-105.

23. Luthman J, Oskarsson A, Olson L, Hoffer B. Postnatal lead exposure affects motor skills and exploratory behavior in rats. Environ Res 1992;58:236-52.

24. Grant LD, Kimmel CA, West GL, Martinez-Vargas CM, Howard JL. Chronic low-level lead toxicity in the rat. Toxicol App Pharm 1980;56:42-58.

25. Dietrich KN, Berger OG, Succop PA, Hammond PB, Bornschein RL. The developmental consequences of low to moderate prenatal and postnatal $\mathrm{Pb}$ exposure: Intellectual attainment in the Cincinnati $\mathrm{Pb}$ study cohort following school entry. Neurotoxicol Teratol 1993;15:37-44. 